\title{
Method to Estimate Mechanical Properties of Glulam on Flexure Testing Based on Its Laminae Characteristics and Position
}

\author{
Effendi Tri Bahtiar ${ }^{l)}$, Naresworo Nugroho ${ }^{\text {I) }}$, Muh Yusram Massijayal), \\ Han Roliandi ${ }^{2)}$, Rentry Augusti $N^{3)}{ }^{3}$, Adi Satriawan ${ }^{3)}$ \\ 1) Faculty of Forestry, Bogor Agricultural University. \\ 2) The Center for Forest Products Research and Develpoment, Ministry of Forestry, Indonesia \\ 3) Alumni of Faculty of Forestry, Bogor Agricultural University \\ e-mail:bahtiar_et@yahoo.com
}

Received 7 September 2010, Revised 2 December 2010, Accepted 15 February 2011

\begin{abstract}
Glulam strength is affected by its laminae characteristics and position. Modulus of Elasticity and Modulus of Rupture of layer system (including glulam) is usually estimated by Transformed cross section (TCS) method recently. But, TCS does not follow the principal due to its contrary assumption related with the reduction of material's plane area for laminae with lower E value and the extension of its plane area for laminae with higher $E$ value. In fact the material properties are independent from its shape and size. Therefore, new calculation method is required. As the relevance, this paper discusses the formulation of a new method to determine the $E$ and $S_{R}$ for glulam based on its laminae properties and position. E and $S_{R}$ calculated by TCS and new method give identical values. The new method confirms the independence of $E$ and $S_{R}$ which could not be fulfilled by TCS. According to this fact, TCS could be replaced by new method. The theoretical E value was higher than its coresponding empirical value, but it has high correlation $\left(R^{2}=68.53 \%\right)$. On the contrary, the theoretical $S_{R}$ value was not significantly different from its coresponding empirical values, but they have poor correlation $\left(R^{2}=27.93 \%\right)$. This condition happened because of finger joint effect on the compression and tension side of the sample. Incorporating the finger joint effect into regression analysis, the equation provides very good prediction. The coefficients of determination were $99.58 \%$ and $97.19 \%$, for $E$ and $S_{R}$ respectively.
\end{abstract}

Keywords: Glulam, Modulus of Elasticity, Modulus of Rupture, Transformed cross section

\section{Introduction}

Solid wood has dimensional limitation problems for construction purpose. Following the demand of large size of wood for construction purposes, then engineered wood products (EWP) are developed, among which glulam with I-shape (Glulam I-Joist). Glulam consists of laminaes those are bundled together and glued. Characteristic and position of each laminaes affects and determines the strength of the resulting glulam resisting the bending load, hence the glulam's strength could be expectedly predicted from its laminae characteristics and position. Modulus of Elasticity (E) and Modulus of Rupture $\left(\mathrm{S}_{\mathrm{R}}\right)$ of EWP with layer system (e.g. glulam) were usually estimated by Transformed cross section (TCS) method recently. But, TCS does not follow the principal due to its assumption that the material properties depend on its shape and size. On TCS methods, laminae's width with lower E value must be reduced and laminae's width with higher $\mathrm{E}$ value must be elongated. In fact, $\mathrm{E}$ denotes material properties which is independent from the size and shape of material, therefore it will not be relevant to change the material's width based on E of laminaes.

Based on above description, new method to calculate $E$ and $S_{R}$ value of glulam was required. This research aims to develop new method to calculate $E$ and $\mathrm{S}_{\mathrm{R}}$ of glulam based on mechanic and geometric analysis. The new method must be applicable in more general case and could be implemented for glulam IJoist besides ordinary (rectangular plane) glulam.

\section{Material and Methods}

This research utilized rubber wood (Hevea brasiliensis) as a raw material and phenol resorcinol formaldehyde (PRF) as adhesive. Rubber wood originated from non productive rubber farm located at West Java. Those woods were cut in rectangular shape to the sizes of $2 \mathrm{~cm} \mathrm{x} 4 \mathrm{~cm} \mathrm{x} 300 \mathrm{~cm}, 2 \mathrm{~cm} \times 6 \mathrm{~cm} \mathrm{x}$ $300 \mathrm{~cm}$, and $2 \mathrm{~cm} \times 8 \mathrm{~cm} \times 300 \mathrm{~cm}$, respectively. Both end sides of each laminae were cut to small specimen for bending test in accordance with the BS-373:1957 ${ }^{1}$ The dimension for each small specimen is $2 \mathrm{~cm} \times 2 \mathrm{~cm}$ x $30 \mathrm{~cm}$.

Laminae were bundled and glued to become glulam I-joist, then bending test conducted with twopoint loading configuration based on ASTM D-1982). There are two types of glulam I-joist with different type of web arrangement. Type 1 set with web as vertically arranged laminae and type 2 set as horizontally arranged laminae (Figure 1). Some laminae must be assembled from two or three pieces of timber because of dimension limitation. On that case, finger joint is applied for end jointing. Average of $\mathrm{E}$ and $\mathrm{S}_{\mathrm{R}}$ (weighted by its length ratio) is taken of the overall $\mathrm{E}$ and $\mathrm{S}_{\mathrm{R}}$ for each laminae. Afterwards, $\mathrm{E}$ and 
$\mathrm{S}_{\mathrm{R}}$ glulam I-joist were calculated by theoretical method and verified by empirical testing.

Theoretical calculation method was done in two ways, comprising transformed cross section (TCS) and new developed method. Meanwhile, empirical values were gained from bending test result based on ASTM D-198, and were calculated using Equation 1 and Equation 2 respectively.

$$
\begin{gathered}
E=\frac{23}{108} \frac{P L^{3}}{\Delta b h^{3}} \\
S_{R}=\frac{P_{\text {maks }} L^{3}}{b h^{2}}
\end{gathered}
$$

Meanwhile, $\mathrm{E}$ and $\mathrm{S}_{\mathrm{R}}$ formula for TCS method employ Equation 3 and 4, respectively.

$$
\begin{aligned}
& E=\frac{I_{x c(t c s)}}{I_{x c}} E_{(r e f)} \\
& S_{R}=b_{r e f} c \frac{I_{t c s}}{I_{a c t}} M I N\left|\frac{S_{R i}}{b_{i(t c s)} y_{i}}\right|
\end{aligned}
$$

Derivation of $E$ and $S_{R}$ formulaes for the new method was conducted through the mechanic and geometry analysis.
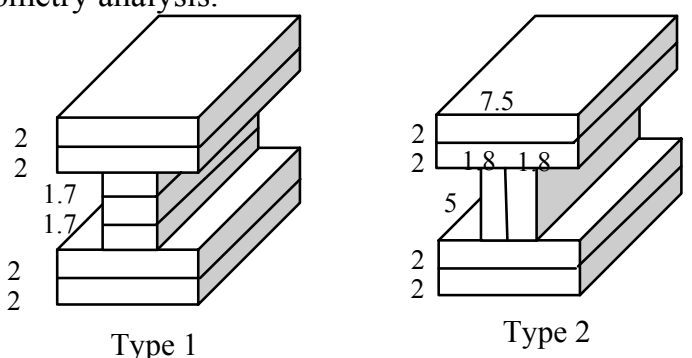

Figure 1. Glulam I-joist shape.

\section{Results and Discussions}

\subsection{Laminae characteristics}

Many reseachers ${ }^{3-6)}$ reported that physical properties such as density and moisture content (MC) affected mechanical properties of wood. In glulam, physical properties of each laminae could affect those of its coresponding glulam. Therefore it is important to report the physical properties of each laminae sample. The physical properties of laminae and glulam which were used in this research are shown in Table 1. Density is calculated based on airdry condition, meanwhile specific gravity is based on ovendry

\begin{tabular}{|c|c|c|c|c|c|c|}
\hline \multirow{2}{*}{$\begin{array}{l}\text { Sample } \\
\text { Code }\end{array}$} & \multicolumn{2}{|c|}{ MC (\%) } & \multicolumn{2}{|c|}{ Density $\left(\mathrm{g} / \mathrm{cm}^{3}\right)$} & \multicolumn{2}{|c|}{ Specific Gravity } \\
\hline & Laminae & Glulam & Laminae & Glulam & Laminae & Glulam \\
\hline G11 & 12.99 & 11.72 & 0.70 & 0.66 & 0.62 & 0.59 \\
\hline G12 & 13.15 & 11.27 & 0.69 & 0.68 & 0.61 & 0.61 \\
\hline G13 & 12.85 & 11.92 & 0.66 & 0.68 & 0.59 & 0.61 \\
\hline G21 & 13.09 & 11.65 & 0.68 & 0.67 & 0.60 & 0.60 \\
\hline G22 & 12.84 & 11.66 & 0.68 & 0.77 & 0.61 & 0.69 \\
\hline G23 & 13.14 & 11.47 & 0.68 & 0.65 & 0.60 & 0.58 \\
\hline Mean & 13.01 & 11.62 & 0.68 & 0.69 & 0.61 & 0.61 \\
\hline
\end{tabular}
condition.

Table 1. Average physical properties of laminae and glulam
Prior to glulam assembling, each the laminaes was cut into small specimen for bending test. Bending test of small specimen was conducted with center point loading configuration based on BS-373:1957. The test result reveals that average $E$ and $S_{R}$ values for small specimen are $8566 \mathrm{MPa}$, and $77 \mathrm{MPa}$, respectively. The summary of $E$ and $S_{R}$ for each laminae is shown in Table 2, while the related details are attached in Appendix 1. Based on its properties, rubber wood could be classified into grade III-II of wood strength

\begin{tabular}{|c|c|c|c|c|c|c|}
\hline \multirow[t]{2}{*}{$\begin{array}{l}\text { Glulam } \\
\text { Code }\end{array}$} & \multicolumn{3}{|c|}{$\begin{array}{l}\text { Modulus of elasticity } \\
\text { (E) (MPa) }\end{array}$} & \multicolumn{3}{|c|}{$\begin{array}{l}\text { Modulus of rupture } \\
\left(\mathrm{S}_{\mathrm{R}}\right)(\mathrm{MPa})\end{array}$} \\
\hline & Min & Max & Mean & Min & Max & Mean \\
\hline G11 & 3130 & 1 & 90 & 26.6 & 99.9 & 79.4 \\
\hline G12 & 10 & 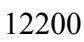 & 85 & 19.6 & 101 & 69.9 \\
\hline G13 & 90 & 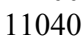 & 84 & 49.2 & 91 & 79.5 \\
\hline G21 & 4520 & 11 & 8992 & 53.1 & 106.7 & 76.7 \\
\hline G22 & 760 & & 7391 & 32.4 & 984.0 & 73.0 \\
\hline G23 & 1055 & 14188 & 8878 & 19.8 & 118.7 & 83.4 \\
\hline & & Mean & 8566 & & Mean & 77.0 \\
\hline
\end{tabular}
classification according to Peraturan Konstruksi Kayu Indonesia (PKKI) NI-5 1961.

Table 2. E and $\mathrm{S}_{\mathrm{R}}$ of laminae for glulam assembling

\subsection{Formulae derivation}

\subsubsection{Modulus elasticity (E) of vertical glulam}

The web of glulam I-joist type 1 consisted of vertically arranged laminae (Figure 1). So it is necessary to develop formula to calculate the $\mathrm{E}$ and $\mathrm{S}_{\mathrm{R}}$ of vertical glulam.

Basic formula for deflection is presented on Equation 5.

$$
E I \frac{d^{2} y}{d x^{2}}=M
$$

For vertical glulam, each changes of laminae's shape due to bending moment parallel to laminae's face must be equal. Therefore, the bending moment deflection formula of each laminae is disclosed on Equation 6.

$$
E_{i} I_{i} \frac{d^{2} y}{d x^{2}}=M_{i} ; i=1,2,3, \ldots, n
$$

Bending moment $(M)$ of vertical glulam distributes into each laminae (Equation 7).

$$
M=\sum_{i=1}^{n} M_{i}
$$

Substituting Equations 5 and 6 into Equation 7, it becomes:

$$
E I=\sum_{i=1}^{n} E_{i} I_{i}
$$

As seen on Figure 1, the laminae on the web has rectangular shape with similar height, so:

$$
I_{i}=\frac{b_{i} h^{3}}{12}
$$

Moment of inertia for vertical glulam could be expressed using Equation 10: 


$$
I=\frac{h^{3}}{12} \sum_{i=1}^{n} b_{i}
$$

Substituting Equations 9 and 10 into Equation 8, Modulus of Elasticity (E) of parallel glulam could be calculated using Equation 11.

$$
E=\frac{\sum_{i=1}^{n} E_{i} b_{i}}{\sum_{i=1}^{n} b_{i}}
$$

Equation 11 is used to determine the $\mathrm{E}$ of web portion of glulam type 1 (Figure 1).

\subsubsection{Modulus of rupture $\left(\mathrm{S}_{\mathrm{R}}\right)$ of vertical glulam}

Modulus of rupture $\left(\mathrm{S}_{\mathrm{R}}\right)$ of vertical glulam is formulated as follow. If Equation 6 is divided by Equation 5, the result is:

$$
M_{i}=M \frac{E_{i} I_{i}}{E I} ; i=1,2,3, \ldots, n
$$

Normal stress occurred on each laminae could be expressed using Equation 13.

$$
\sigma_{i}=\frac{M_{i} y_{i}}{I_{i}} ; i=1,2,3, \ldots, n
$$

Substituting Equation 12 into Equation 13, it becomes:

$$
\sigma_{i}=\frac{M y_{i}}{I} \frac{E_{i}}{E} ; i=1,2,3, \ldots, n
$$

Maximum normal stress for each laminae occurred on its upper and lower portion fiber, which could be expressed as a half height of vertical glulam (Equation $15)$.

$$
y_{i(\text { maks })}=\frac{h}{2}
$$

Hence, maximum normal stress was calculated by substituting Equations 10 and 15 into Equation 14.

$$
\sigma_{i(\text { maks })}=\frac{6 M}{h^{2} \sum_{i=1}^{n} b_{i}} \frac{E_{i}}{E}
$$

Damage that occured when maximum normal stress of each lamina is lower than its bending strength parallel to grain $\left(\sigma_{i(\max )} \leq S_{R i / /}\right)$. Therefore, the biggest moment which may be resisted by glulam is the minimum moment value of each laminae $\left(M_{\min }\right)$ :

$$
M_{\text {min }}=\operatorname{MIN}\left(\frac{S_{R_{i}}}{E_{i}}\right)\left(\frac{E h^{2}}{6} \sum_{i=1}^{n} b_{i}\right) ; i=1,2,3, \ldots, n
$$

Modulus of rupture $\left(S_{R}\right)$ of vertical glulam is calculated by substituting Equation 17 into 16:

$$
S_{R}=\operatorname{MIN}\left(S_{R_{i}}\right)
$$

Equation 18 concludes that the $\mathrm{S}_{\mathrm{R}}$ of vertical glulam is similar to the weakest laminae, which has lowest $\mathrm{S}_{\mathrm{R}}$. It is consistent with the weakest link theory, whereby the sequence of events or objects is dependent on the support of the whole, and the whole is only as reliable as the weakest member or link ${ }^{7,8)}$.

\subsubsection{Modulus of Elasticity (E) of Horizontal Glulam}

As seen on Figure 1, most laminaes were arranged perpendicular to the moment which made up horizontal glulam. The bending equation for this condition is formulated as follows. Figure 2 shows glulam deflection as a result of bending moment. If $R$ is deflection radius, and $x_{0}$ is initial of glulam length, thus on above neutral line shortening may occur and under neutral line will occur prolongation. If fiber distance $(y)$ under neutral line marked with positive sign $\left(+y_{i}\right)$ and above neutral line marked with negative sign $\left(-y_{i}\right)$, based on geometric analysis, the condition could be formulated by Equation 19 (Figure 2).

$$
\begin{aligned}
& \frac{R}{x_{0}}=\frac{R+y_{1}}{x_{1}} \\
& =\frac{R+y_{2}}{x_{2}}=\ldots=\frac{R+\left(-y_{5}\right)}{x_{5}}=\frac{R+y_{i}}{x_{i}}
\end{aligned}
$$

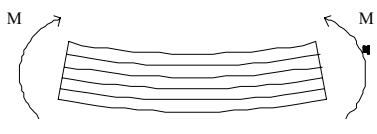

Figure 2. Deflection on horizontal glulam

Equation 19 could be modified to calculate the strain of each laminae $\left(\varepsilon_{i}\right)$ :

$$
\varepsilon_{i}=\frac{\Delta x_{i}}{x_{0}}=\frac{x_{i}-x_{0}}{x_{0}}=\frac{y_{i}}{R}
$$

Substituting Hooke's law into Equation 20:

$$
\sigma_{i}=E_{i} \varepsilon_{i}=E_{i} \frac{y_{i}}{R}
$$

Internal moment for each of the laminaes could be expressed by Equation 22 .

$$
M_{i}=y_{i} \sigma_{i} d A_{i} ; i=1,2,3, \ldots, n
$$

Therefore, total moment of each laminae:

$$
M_{i(\text { total })}=\int y_{i} \sigma_{i} d A_{i} ; i=1,2,3, \ldots, n
$$

and total value for internal moment excerted at all cross-sectioned plane:

$$
M_{(\text {total })}=\sum_{i=1}^{n}\left(\int y_{i} \sigma_{i} d A_{i}\right)
$$

Substituting equation 21 into equation 24:

$$
M_{(\text {total })}=\sum_{i=l}^{n}\left(\frac{E_{i}}{R} \int y_{i}^{2} d A_{i}\right)
$$

By definition, moment inertia $(I)$ is formulated as follow:

$$
I_{i}=\int y_{i}^{2} d A_{i}
$$


$R$ could be calculated by substituting Equation 26 into Equation 25:

$$
R=\frac{\sum_{i=1}^{n} E_{i} I_{i}}{M_{(\text {total })}}
$$

$R$ value for glulam and its laminae is similar, hence $R$ for glulam:

$$
R=\frac{E I}{M_{(\text {total })}}
$$

$R$ could be eliminated by substituting Equation 27 into Equation 28, so Modulus of elasticity $(E)$ for horizontal glulam could be calculated by Equation 29:

$$
E=\frac{\sum_{i=1}^{n} E_{i} I_{i}}{I}
$$

\subsubsection{Modulus of rupture $\left(\mathrm{S}_{\mathrm{R}}\right)$ of horizontal glulam}

Modulus of rupture $\left(S_{R}\right)$ equation for glulam with horizontally arranged laminae is formulated through the following discussion. The stress on each laminae could be calculated by substituting Equation 28 into Equation 21:

$$
\sigma_{i}=\frac{E_{i}}{E} \frac{M_{(\text {total })} y_{i}}{I}
$$

In order to avoid the damage, laminae's normal stress shall be lower than bending strength of each laminae $\left(\sigma_{i} \leq S_{R i}\right)$. Therefore, the bending strength formula becomes:

$$
\frac{E_{i}}{E} \frac{M_{(\text {total })} y_{i}}{I} \leq S_{R_{i}} ; i=1,2,3, \ldots, n
$$

The highest total moment that can be resisted by glulam depends upon the minimum moment which appears on each laminae $\left(\mathrm{M}_{\mathrm{min}}\right)$ :

$$
M_{(\min )}=\operatorname{MIN}\left|\frac{S_{R_{i}}}{E_{i} y_{i}}\right|(E I) ; i=1,2,3, \ldots, n
$$

Modulus of rupture $\left(\mathrm{S}_{\mathrm{R}}\right)$ of glulam is defined as stress which occurs on outer fiber of glulam assembly. If the distance of outer fiber from neutral axis is denoted by " $y$ ", so the $\mathrm{S}_{\mathrm{R}}$ of glulam could be expressed by Equation 33:

$$
S_{R}=\frac{M_{(\min )} y}{I}
$$

Subtituting Equation 32 into 33:

$$
S_{R}=E y\left(\operatorname{MIN}\left|\frac{S_{R_{i}}}{E_{i} y_{i}}\right|\right)
$$

Based on Equation 34, the value of " $y_{i}$ and $y$ " variables have been still undefined. In order to define the " $y_{i}$ and $y$ " variables, the neutral line shall be identified. If the compressive stress denotes by positive value and tensile stress denotes by negatif value, resultant stress on cross sectional plane area must be equal to 0 (zero) because of the equilibrium condition. The total of tensile stress shall be equal with compression stress, therefore:

$$
\int \sigma_{i} d A=\frac{M_{\text {total }} y}{E I} \sum_{i=1}^{n}\left(E_{i} \int y_{i} d A_{i}\right)=0
$$

For I-plane with different width on each lamina, the formula becomes:

$$
\frac{M_{\text {total }} y}{E I} \sum_{i=I}^{n}\left(E_{i} b_{i} \int_{i=1}^{n} \int_{i=1}^{n-1} y_{i} d y\right)=0
$$

Since all variables outside the sigma sign are not equal to 0 , then:

$$
\sum_{i=1}^{n}\left(E_{i} b_{i} \int_{i=1}^{\sum_{i=1}^{n} h_{i}} y_{i} d y\right)=0
$$

An assisting line is needed to solve Equation 37. The assisting line is located at the bottom side of back laminae. Integrating Equation 37, we get Equation 38. Notation $c$ denotes neutral axis position, measured from the assisting line (bottom line).

$$
\sum_{i=1}^{n} E_{i} b_{i}\left(\left(\sum_{i=1}^{n} h_{i}-c\right)^{2}-\left(\sum_{i=1}^{n-1} h_{i}-c\right)^{2}\right)=0
$$

Equation 38 is a quadratic function, which could be solved and become:

$$
c=\frac{\sum_{i=1}^{n} E_{i} b_{i}\left(\left(\sum_{i=1}^{n} h_{i}\right)^{2}-\left(\sum_{i=1}^{n-1} h_{i}\right)^{2}\right)}{2\left(\sum_{i=1}^{n} E_{i} h_{i} b_{i}\right)}
$$

As mentioned above, " $y$ " variable is the distance of outer fiber to neutral line and " $y_{i}$ " is distance of $i$-th fiber to neutral line. If the assisting line is bottom line, then " $y$ " variable has similar value with neutral line $(c)$. Finally Modulus of rupture $\left(\mathrm{S}_{\mathrm{R}}\right)$ of horizontal glulam could be calculated by Equation 40 . Equation 40 is then formulated by replacing $y$ on Equation 34 with $c$ :

$$
S_{R}=E c\left(\operatorname{MIN}\left|\frac{S_{R_{i}}}{E_{i} y_{i}}\right|\right)
$$

\subsection{Application of TCS method}

Transformed cross section (TCS) method needs a reference laminae as a standard width while the width of another laminae would be shortened or elongated based on its E. The width of laminae which has lower $E$ than that of the reference laminae would be shortened, and laminae width which has higher $\mathrm{E}$ would be elongated.

On TCS methods, there are 6 (six) steps to calculate the $\mathrm{E}$ and $\mathrm{S}_{\mathrm{R}}$ of glulam, namely:

1. Identifying the actual size and $E$ of each laminae.

2. Transforming the width of each laminae based on its E-ratio. 
3. Calculating neutral axis and moment inertia of transformed glulam cross-sectional plane.

4. Calculating neutral axis and moment inertia of glulam for empirical testing based on actual glulam cross-sectional plane.

5. Calculating E of glulam by Equation 3 .

6. Calculating $S_{R}$ of glulam by Equation 4 .

In this research, TCS applied twice: (1) face laminae choosen as reference, and (2) back laminae chosen as reference. TCS give identical result when face or back is taken as reference laminae. The result is reported in Table 3. This condition proves Bodig and Jayne (1993) and other reseacher ${ }^{9-10)}$ statement that TCS method will give identical result about $E$ and $S_{R}$ of layer system no matter which reference laminae was chosen. On the contrary, another reseacher reported different $\mathrm{E}$ of glulam if the back or face laminae was choosen as reference, therefore a piece of glulam will have different $E$ value coresponding to the number of its laminae. It is confusing very much if a piece of material has many E value.

Table 3. Theoretical $\mathrm{E}$ and $\mathrm{S}_{\mathrm{R}}$ of Glulam calculated by TCS and New Method

\begin{tabular}{cccccc}
\hline \multirow{2}{*}{ Type } & $\begin{array}{c}\text { Glulam } \\
\text { Code }\end{array}$ & \multicolumn{2}{c}{$\mathrm{E}(\mathrm{MPa})$} & \multicolumn{2}{c}{$\mathrm{S}_{\mathrm{R}}(\mathrm{MPa})$} \\
\cline { 3 - 6 } & TCS & $\begin{array}{c}\text { New } \\
\text { Method }\end{array}$ & TCS & $\begin{array}{c}\text { New } \\
\text { Method }\end{array}$ \\
\hline 1 & G11 & 7982 & 7982 & 84 & 84 \\
& G12 & 10222 & 10222 & 103 & 103 \\
& G13 & 7363 & 7363 & 77 & 77 \\
& Average & 8522 & 8522 & 88.0 & 88.0 \\
\hline 2 & G21 & 7406 & 7406 & 79 & 79 \\
& G22 & 7403 & 7403 & 79 & 79 \\
& G23 & 7406 & 7406 & 94 & 94 \\
& Average & 7330 & 7330 & 83.8 & 83.8 \\
\hline
\end{tabular}

\subsection{Application of new method}

Although TCS is well known already as a standard method to calculate $E$ and $S_{R}$ of layer system, it has a fatal weakness because of its inconsistency with basic science. $E$ and $S_{R}$ are material properties which are independent from its shape and size. This condition could not be fulfilled by TCS because the method changes the size (width) of cross-sectional plane of laminae depend on its E. That's why it is important to develop a new method which is more consistent with basic science. The formulae derivation of a new method to calculate the $E$ and $S_{R}$ of glulam has been describe above. Equations 11 and 18 are suitable to calculate $\mathrm{E}$ and $\mathrm{S}_{\mathrm{R}}$ of vertical glulam, respectively, while Equations 29 and 40 are suitable for horizontal glulam. More complex layer system could be solved by the combination of those equations.

On the new methods, there are 6 (six) steps to calculate the E of glulam, namely:

1. Identifying the actual size and $\mathrm{E}$ of each laminae.

2. Calculating the theoretical neutral axis of glulam by Equation 39.
3. Calculating moment inertia $\left(\mathrm{I}_{\mathrm{xc}}\right)$ of each laminae based on glulam theoretical neutral axis, using parallel axis theory.

4. Calculating neutral axis and moment inertia of glulam for empirical testing based on actual glulam cross-sectional plane.

5. Calculating E of glulam by Equation 11 for vertical glulam, and Equation 29 for horizontal glulam.

6. Calculating $\mathrm{S}_{\mathrm{R}}$ of glulam by Equation 18 for vertical glulam and Equation 40 for horizontal glulam.

The detail steps examples for aplication of the new method is shown in Appendix 2 and 3, for glulam type 1 and 2, respectively. And the result is shown in Table 3.

As seen on Table 3, the new method gives identical results with those of TCS. Theoretical E and $S_{R}$ calculated by TCS or new method give identical result. It means, the new method could replace TCS method to calculate $\mathrm{E}$ of layer system because they bring out identical value, and all of its steps confirm the independence of material properties from its size and shape.

\subsection{Empirical verification}

Verifying the theoretical value by empirical testing was conducted on this research, and the result is shown in Table 4. As seen on Table 4, the empirical value of $\mathrm{E}$ is about $30 \%$ lower in average than the theoretical value. Paired t-test value confirm the significant different betwen those values $(p=0.0276)$, but they have high correlation $(\mathrm{r}=82.78 \%)$. Figure 5a confirms that the theoretical E value could predict the empirical $E$ value with $68.53 \%$ coefficient of determination. On the contrary, the theoretical value of $\mathrm{S}_{\mathrm{R}}$ had no significant different from the empirical value, which was proven by paired t-test $(\mathrm{p}=0.2998)$. However the Pearson's correlation is low $(\mathrm{r}=52.85 \%)$ and the coefficient of determination is $27.93 \%$, so the linier regression was not a good fit enough to determine the empirical $S_{R}$ value based on its theoretical value only (Figure $5 \mathrm{~b}$ ). This condition occurs because of the joint effects which influence the mechanical properties of glulam. On this research, joint effects were defined as number of joints multiplied by the vertical distance of outer surface of each laminae and divided by its length (Equation 41).

$$
J=\frac{n_{i} y_{i}}{L_{i}} \times 100 \%
$$

Where $J$ joint effect $(\%), n_{i}$ amount of joint on each laminae, $y_{i}$ distance of outer laminae from theoretical neutral axis $(\mathrm{cm}), L_{i}$ laminae length $(\mathrm{cm})$. J value bellow neutral axis is called finger joint effect under tension and above neutral axis is called finger joint effect under compression. The both value is shown in Table 4. 
Table 4. Empirical verification of Modulus of elasticity (E) and Modulus of rupture $\left(\mathrm{S}_{\mathrm{R}}\right)$ of the glulam

\begin{tabular}{ccccccc}
\hline \multirow{2}{*}{$\begin{array}{c}\text { Sample } \\
\text { Code }\end{array}$} & \multicolumn{2}{c}{$\mathrm{J}(\%)$} & \multicolumn{2}{c}{$\mathrm{E}(\mathrm{MPa})$} & \multicolumn{2}{c}{$\mathrm{S}_{\mathrm{R}}(\mathrm{MPa})$} \\
\cline { 2 - 7 } & $\begin{array}{c}\text { Com- } \\
\text { pression }\end{array}$ & $\begin{array}{c}\text { Ten- } \\
\text { sion }\end{array}$ & $\begin{array}{c}\text { Theo- } \\
\text { retic }\end{array}$ & Empiric & \multicolumn{2}{c}{$\begin{array}{c}\text { Theo- } \\
\text { retic }\end{array}$} \\
\hline G11 & 3.65 & 3.71 & 7982 & 7174 & 83.67 & 81.98 \\
G12 & 2.21 & 3.18 & 10222 & 9584 & 103.42 & 89.28 \\
G13 & 3.40 & 2.47 & 7363 & 3186 & 76.90 & 72.10 \\
Mean & 3.09 & 3.12 & 8522 & 6648 & 88.00 & 81.12 \\
\hline G21 & 3.94 & 4.11 & 7406 & 6728 & 78.91 & 89.8 \\
G22 & 2.04 & 2.85 & 7181 & 2426 & 78.91 & 42.82 \\
G23 & 3.28 & 3.20 & 7403 & 4157 & 93.56 & 93.73 \\
Mean & 3.09 & 3.39 & 7330 & 4437 & 83.79 & 75.45 \\
\hline
\end{tabular}

Incorporating finger joint effect under tension and compression into regression analysis, this bring out Equation 42. It is a very good fit regression equation because it could predict the empirical E with $99.58 \%$ coefficient of determination (Figure 6a). Further analysis shows that Finger joint effect on compression didn't give significant effect to empirical E (Table 6). Empirical E value depends on its theoretical value and its finger joint effect on tension.

$$
\begin{aligned}
& \mathrm{E}=-20092+2.14 \mathrm{E}^{\prime}+1890.05 \mathrm{~F}_{\mathrm{t}}+810.82 \mathrm{~F}_{\mathrm{c}} \\
& \left(\mathrm{R}^{2}=99.58\right)
\end{aligned}
$$

Similar analysis was conducted on empirical $S_{R}$ value, and this results in Equation 43. The regression equation is a very good fit because it can predict the empirical $S_{R}$ value with high coefficient of determination $\left(\mathrm{R}^{2}=97.19 \%\right)$ (Figure $\left.6 \mathrm{~b}\right)$. On this case, finger joint under tension doesn't give significant effect to empirical $S_{R}$, but theoretical $S_{R}$ value and finger joint under compression give significant effect (Table 6)

$$
\begin{aligned}
& \mathrm{S}_{\mathrm{R}}=-129.97+1.62 \mathrm{~S}_{\mathrm{R}}+0.14 \mathrm{~F}_{\mathrm{t}}+22.15 \mathrm{~F}_{\mathrm{c}} ; \\
& \left(\mathrm{R}^{2}=97.19\right)
\end{aligned}
$$

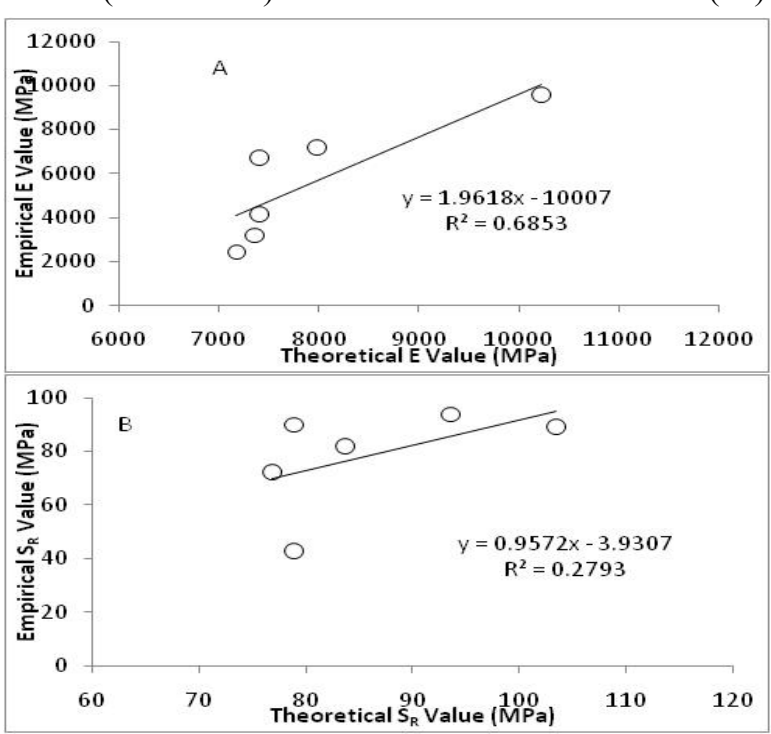

Figure 5. Linier Regression between Theoretical and Empirical Value of Glulam I-Joist (a. Modulus of

\begin{tabular}{|c|c|c|c|c|c|}
\hline & $d f$ & $S S$ & $M S$ & $F$ & Sig. $F$ \\
\hline Regression & 3 & 37433371 & 12477790 & $\left.159^{* *}\right)$ & 0.006 \\
\hline $\begin{array}{l}\text { Theoretical E } \\
\text { Value }\end{array}$ & 1 & 25759367 & 25759367 & $\left.329^{* *}\right)$ & 0.003 \\
\hline $\begin{array}{l}\text { Finger Joint on } \\
\text { Tension }\end{array}$ & 1 & 10661455 & 10661455 & $\left.136^{* *}\right)$ & 0.007 \\
\hline $\begin{array}{l}\text { Finger Joint on } \\
\text { Compression }\end{array}$ & 1 & 1012550 & 1012550 & $13^{\mathrm{ns})}$ & 0.069 \\
\hline$\underline{\text { Residual }}$ & 2 & 156504 & 78252 & & \\
\hline Total & 5 & 37589875 & & & \\
\hline
\end{tabular}
Elasticity $(\mathrm{E})$; b. Modulus of Rupture $\left(\mathrm{S}_{\mathrm{R}}\right)$ )
Table 5. Anova of empirical verification for Modulus of elasticity of the glulam

\begin{tabular}{|c|c|c|c|c|c|}
\hline & $d f$ & $S S$ & $M S$ & $F$ & Sig. $F$ \\
\hline Regression & 3 & 1751 & 584 & $\left.23^{*}\right)$ & 0.042 \\
\hline Theoretical E & 1 & & & & \\
\hline Value & & 503 & 503 & $\left.20^{*}\right)$ & 0.047 \\
\hline Finger Joint on & 1 & & & & \\
\hline Tension & & 451 & 451 & $18^{\text {ns) }}$ & 0.052 \\
\hline Finger Joint on & 1 & & & & \\
\hline Compression & & 796 & 796 & $\left.31^{*}\right)$ & 0.030 \\
\hline Residual & 2 & 51 & 25 & & \\
\hline Total & 5 & 1802 & & & \\
\hline
\end{tabular}

Table 6. Anova of empirical verification for Modulus of rupture of the glulam

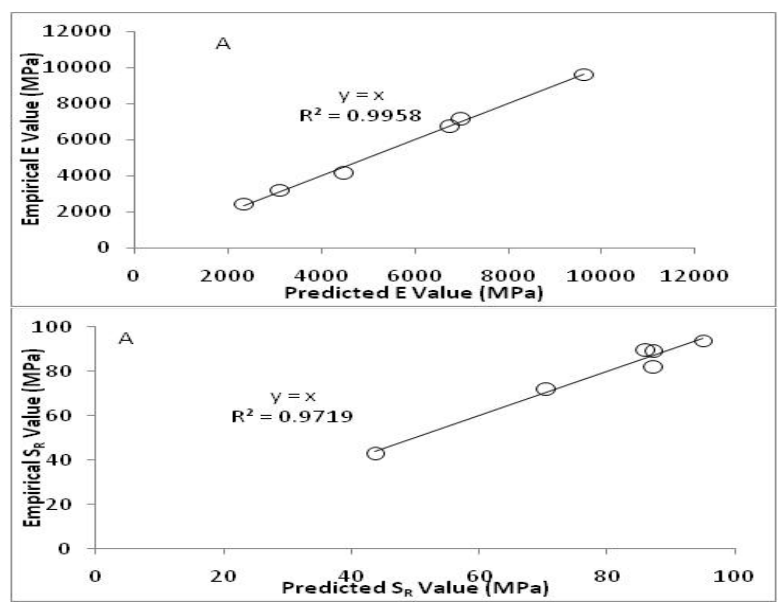

Figure 6. Linier Regression between Corrected Theoretical and Empirical Value of Glulam I-Joist (a. Modulus of Elasticity (E); b. Modulus of Rupture $\left(\mathrm{S}_{\mathrm{R}}\right)$ )

\section{Conclusion}

This research comes up with a new method to calculate the Modulus of elasticity (E) and Modulus of rupture $\left(S_{R}\right)$ for layer system in order to substitute for the transformed cross section (TCS) method. Both methods provides identical results. The new method is proven by mechanic and geometric analysis and consistent with independence of material properties, which could not be fulfilled by TCS method.

Empirical test verified the theoretical E value which is higher than the empirical value, however they have high correlation $\left(\mathrm{R}^{2}=68.53 \%\right)$. On the contrary, the theoretical $S_{R}$ value is not significantly different from its empirical value, but it has poor correlation $\left(\mathrm{R}^{2}=27.93 \%\right)$. This condition is happened because of 
finger joint effect under the compression and tension side of the sample.

Incorporating finger joint effect into regression analysis, the equation results in a very good prediction. The coeffient of determination is $99.58 \%$ and $97.19 \%$, for $E$ and $S_{R}$ respectively. The theoretical values of $E$ and $S_{R}$ afford significant effect on its empirical value. Meanwhile, the finger joint effect under tension provides significant effect on empirical E value only, and finger joint effect under compression offers significant effect to empirical $S_{R}$ value only.

\section{References}

1. British Standard. Methods of testing small clear specimens of timber. BS 373:1957.

2. American Society for Testing and Material. Standard Test Methods of Static Tests of Lumber in Structural Sizes. ASTM D198-05. 2005.

3. Ülker Usta. The Effect of Moisture Content and Wood Density on the Preservative Uptake of Caucasian fir (Abies nordmanniana (Link.) Spach.) Treated with CCA, Turkish Journal of Agriculture and Forestry, Turkey, 28, 1-7, 2004.

4. B. Ajayi et al., Effect of Wood Density on Bending Strength and Dimensional Movement of Flake Boards from Gmelina arborea, and Leuceana leucocephala, $11^{\text {th }}$ Inorganic-Bonded
Fiber Composite Conference. Madrid, Spain, 2008, November 5-7, 2008.

5. John Turner, Wood properties and their implications for wood use (particularly in relation to radiata pine). NZ Timber Design Journal, Vol 13(1), 15-18, 2008.

6. R. Washusen et al., Relationships between Density, Shrinkage, Extractives Content and Microfibril Angle in Tension Wood from Three Provenances of 10-Year-Old Eucalyptus globulus Labill, 55(2), 176-182, 2001.

7. S.B. Batdorf, H.L. HeninischJR., Weakest Link Theory Reformulated for Arbitrary Fracture Criterion, Journal of the American Ceramic Society, 61(7-8), 355-358, 1978.

8. Won Suh, The Weakest-Link Theory and Distribution of Bundle Strength, Textile Research Journal, 42, pp. 438-441, 1972.

9. J. Bodig, B. A. Jayne, Mechanics of Wood and Wood Composites,: Van Nostrand Reinhold Company, New York, 1982.

10. N. C. James, Yena Shing-Chung, The bending stiffness of laminated composite material I-beams, Composite Engineering, 3(11), 1025-1033, 1035 1038, 1993. 
Table 7. Bending test result of small specimens related with its place on Glulam I-joist Type 1 (G11, G12, G13) and Type 2 (G21, G22, G23)
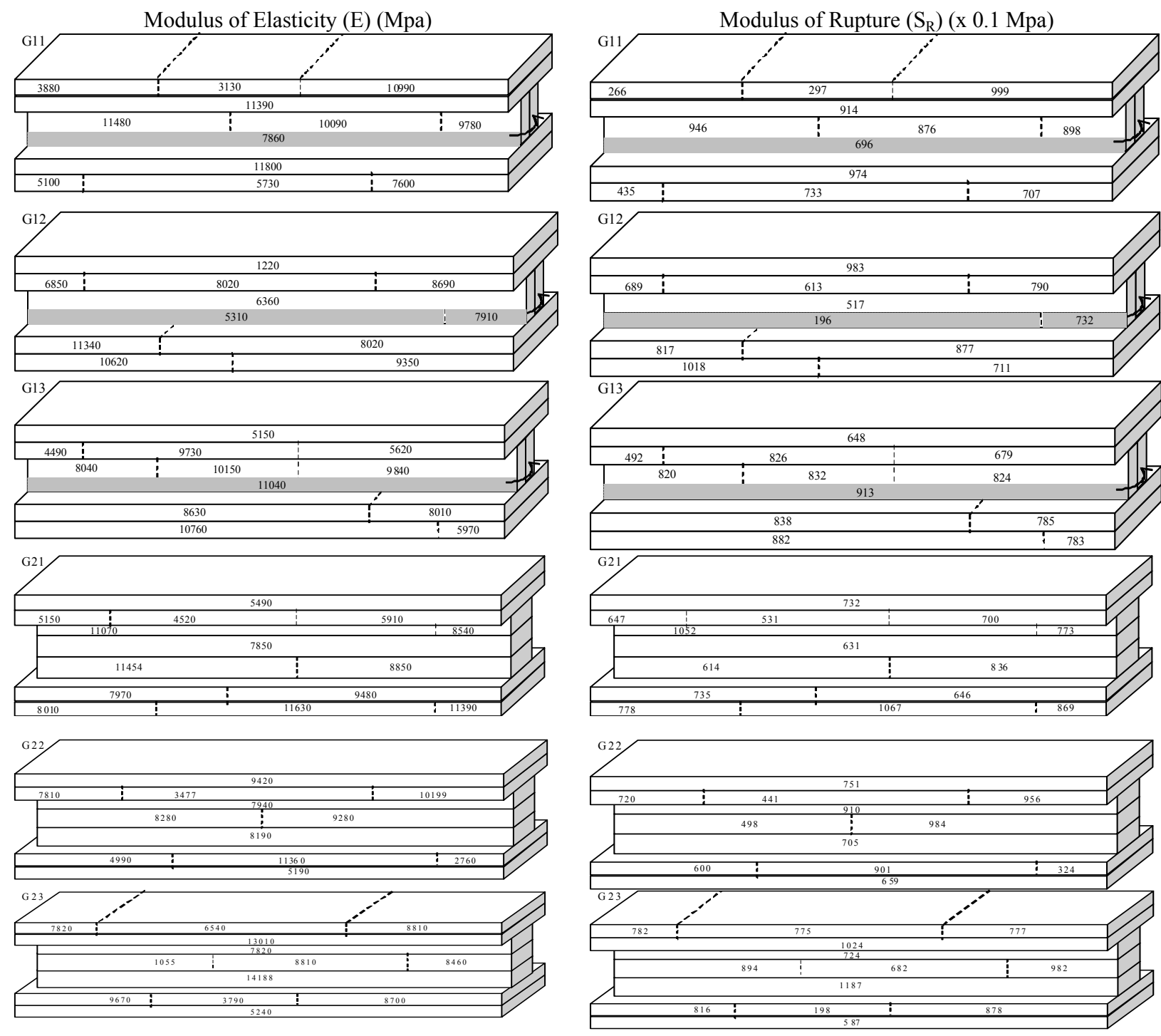

Table 8. Example Detail of TCS Methods to calculate the E of type 2 Glulam.

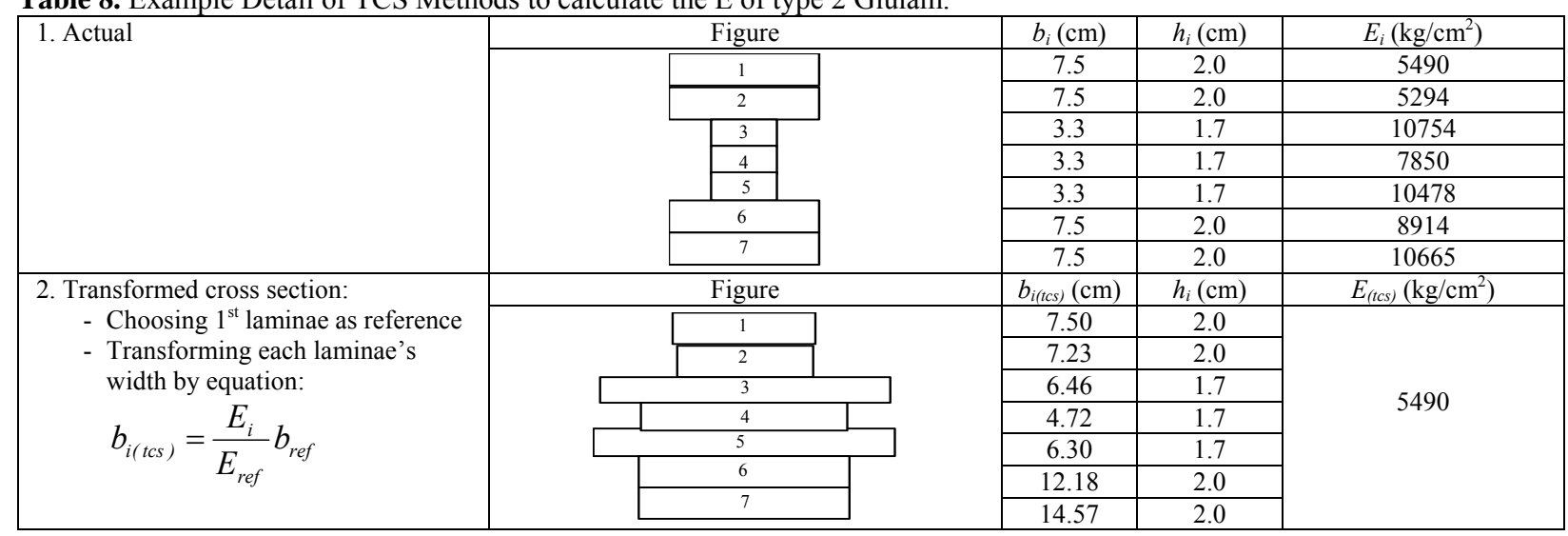


Table 8. Continued

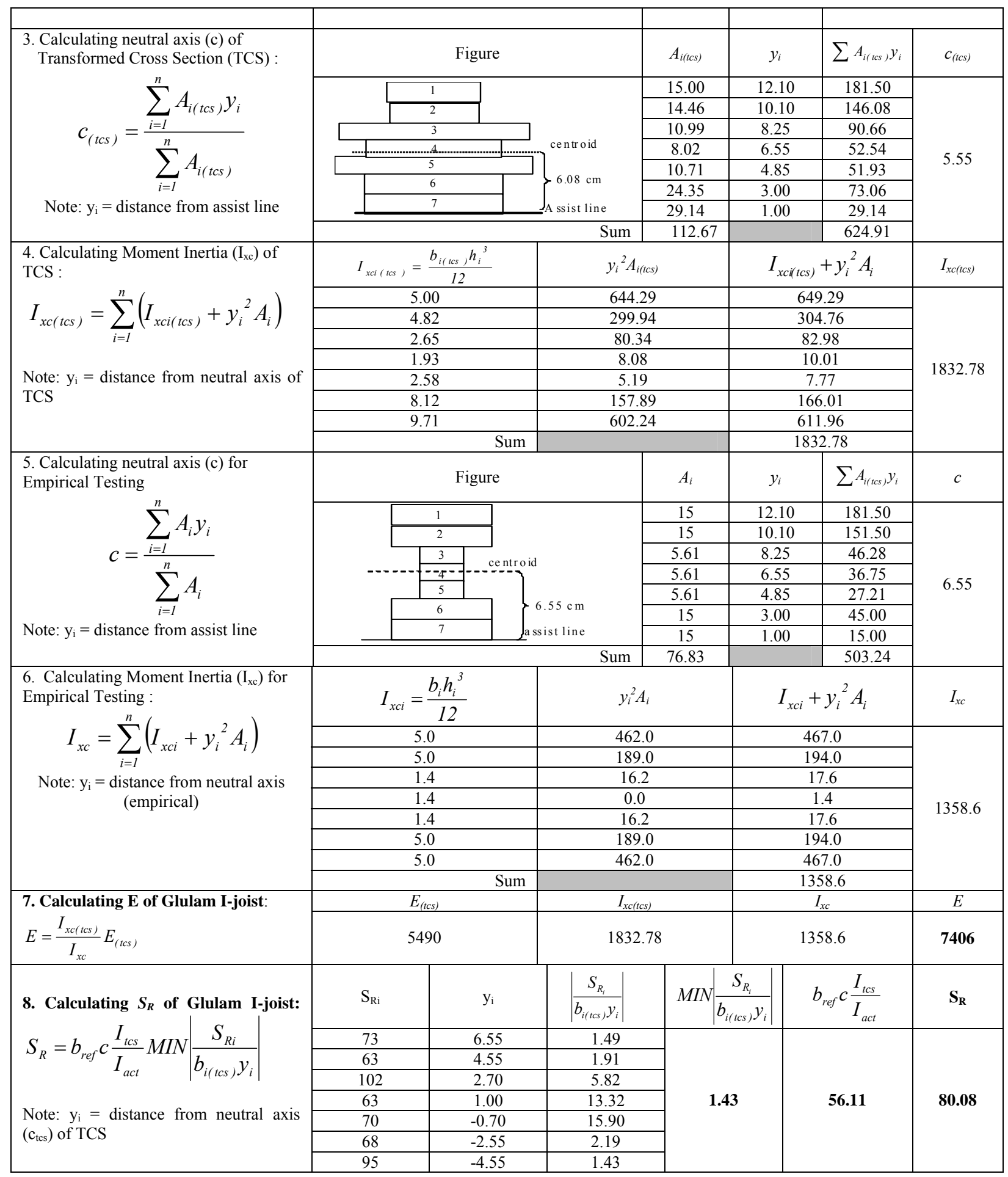


Table 9. Example Detail of New Method to calculate the E of type 2 Glulam.

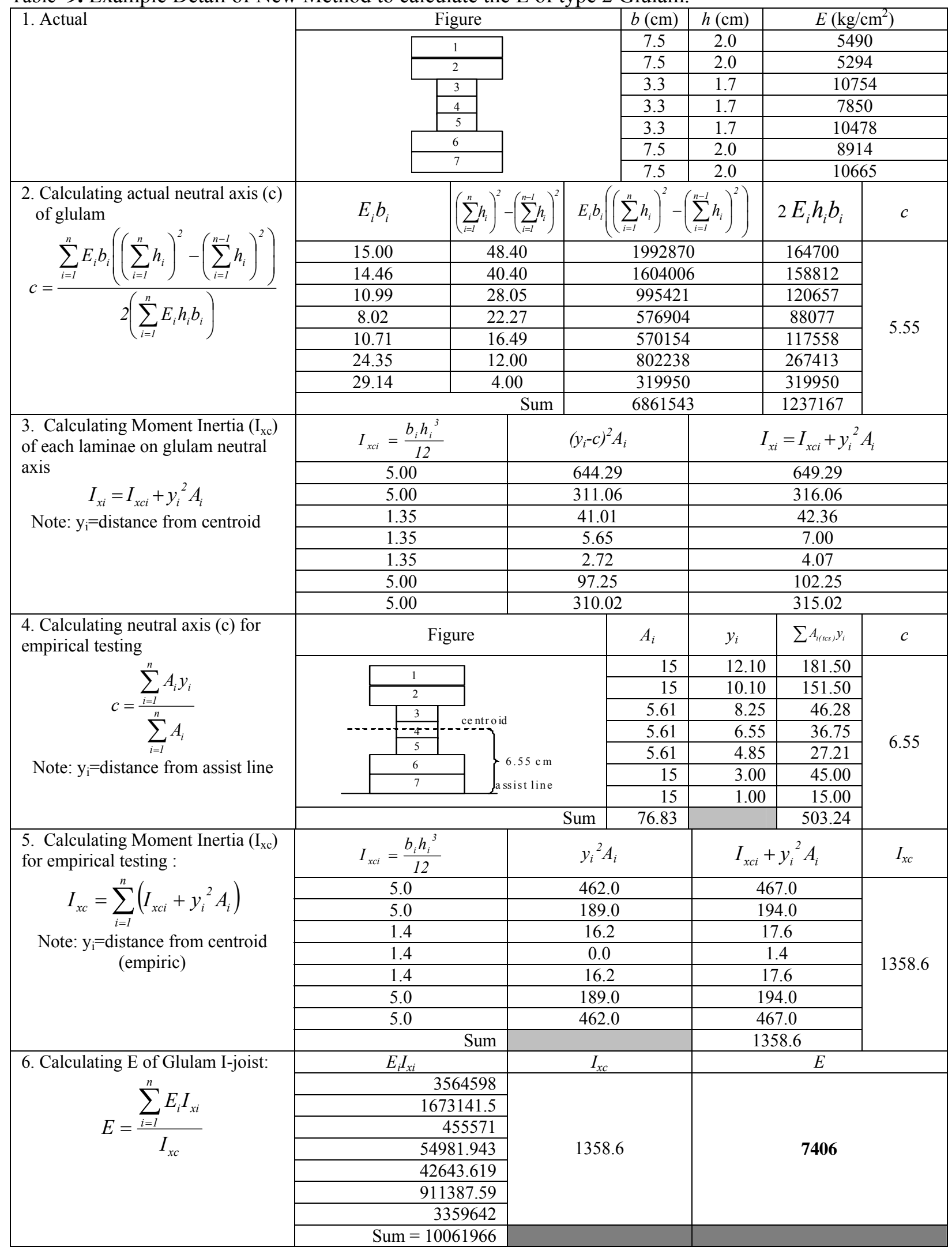


Table 9. Continued

\begin{tabular}{|c|c|c|c|c|c|c|}
\hline 7. Calculating SR by Equation: & $\mathrm{S}_{\mathrm{Ri}}$ & $\mathrm{y}_{\mathrm{i}}$ & $\left|\frac{S_{R_{i}}}{E_{i} y_{i}}\right|$ & $\operatorname{MIN}\left|\frac{S_{R_{i}}}{E_{i} y_{i}}\right|$ & Ec & $\mathrm{S}_{\mathrm{R}}$ \\
\hline \multirow{6}{*}{$\begin{array}{l}S_{R}=E c\left(M I N\left|\frac{S_{R_{i}}}{E_{i} y_{i}}\right|\right) \\
\begin{array}{l}\text { Note: yi }=\text { distance from actual } \\
\text { centroid }\end{array}\end{array}$} & 73.2 & 6.55 & 0.00203 & \multirow{6}{*}{0.00195} & \multirow{6}{*}{41074.8} & \multirow{6}{*}{80.08} \\
\hline & 63.0 & 4.55 & 0.00261 & & & \\
\hline & 101.7 & 2.70 & 0.00350 & & & \\
\hline & 63.1 & 1.00 & 0.00801 & & & \\
\hline & 69.7 & -0.70 & 0.00956 & & & \\
\hline & $\begin{array}{l}67.9 \\
94.5\end{array}$ & $\begin{array}{l}-2.55 \\
-4.55\end{array}$ & $\begin{array}{l}0.00299 \\
0.00195\end{array}$ & & & \\
\hline
\end{tabular}

